\title{
Traumatic Pneumorrhachis
}

\author{
Sianny Suryawati \\ Department Radiologi Fakultas Kedokteran Universitas Wijaya Kusuma Surabaya \\ e-mail: sianny.spr@gmail.com
}

\begin{abstract}
Abstrak
Pneumorrhachis $(P R)$, yang merupakan entrapment udara atau gas dalam canalis spinalis, adalah kondisi yang jarang terjadi, dan biasanya dihubungkan dengan trauma dan prosedur pembedahan. Udara intraspinal biasanya dapat ditemukan tersendiri di regio servikal, thorakal, maupun lumbosakral (lebih jarang), namun dapat pula ditemukan di seluruh canalis spinalis. Patogenesis dan etiologi kelainan ini sangat bervariasi dan menimbulkan tantangan dalam diagnosisnya. Prosedur diagnosis pilihan pada keadaan ini adalah CT spinal. Pneumorrhachis biasanya tidak menimbulkan gejala, namun keberadaannya juga dapat mencerminkan adanya pathologi serius yang mendasarinya. Kelainan dasar ini dapat tersamarkan dan harus diperiksa dengan hati-hati agar dapat memberikan terapi yang adekuat. Laporan kasus ini memaparkan kasus jarang traumatic pneumorrhachis pada wanita usia 63 tahun setelah jatuh dari ketinggian yang tidak diketahui dan dibawa ke Instalasi Gawat Darurat dalam keadaan tidak sadarkan diri. CT scan thoracoabdominal menunjukkan adanya fraktur tulang multiple, pneumothorax dan contussio pulmonum, pneumomediastinum, emphysema subcutan luas, dan juga dissecting aortic aneurysm. Karena traumatic pneumorrhachis seringkali disertai trauma berat yang mendasarinya, seperti yang ditemukan pada laporan kasus ini, maka evaluasi mendalam perlu dilakukan untuk menemukan adanya jejas lainya, dan ahli bedah saraf tulang belakang harus memberikan perhatian untuk mencegah komplikasi berupa meningitis dan pneumocephalus.
\end{abstract}

Kata Kunci: Pneumorrhacis, udara intraspinal, canalis spinalis

\section{Traumatic Pneumorrhachis}

\begin{abstract}
Traumatic pneumorrhachis (PR) is a rare clinical entity but eminent radiographic finding, which involves the entrapment of air or gas within the spinal canal. Intraspinal air is usually found isolated not only in the cervical, thoracic and, less frequently, the lumbosacral regions but can also be located in the entire spinal canal. The pathogenesis and etiology of this uncommon entity vary and may present a diagnostic challenge. The diagnostic procedure should include spinal $C T$, the imaging tool of choice. PR usually represents an asymptomatic epiphenomenon but can also be symptomatic by itself as well as by its underlying pathology. The latter, although often severe, might be concealed and has to be examined carefully to enable adequate patient treatment. Here we report a rare case of traumatic $P R$ in a 63 year old woman following a fall of unknown height in household accident in Surabaya, Indonesia, who came unconscious at our Emergency Department. Thoracoabdominal computed tomography (CT) scan showed multiple bone fractures, pneumothorax and contussio pulmonum, pneumomediastinum, extensive subcutaneous emphysema, and also a dissecting aortic aneurysm. Since Traumatic pneumorrhachis is often accompanied by underlying severe
\end{abstract}


Traumatic Pneumorrhachis

Sianny Suryawati

trauma, as in this case report, meticulous evaluation is needed to find concomitant injuries, and spine surgeons should pay careful attention to prevent meningitis and tension pneumocephalus.

Keywords: Pneumorrhachis, Intraspinal air, Spinal canal

\section{PENDAHULUAN}

Pneumorrhachis $\quad(P R)$, yang merupakan entrapment udara atau gas dalam canalis spinalis, adalah kondisi yang jarang terjadi, dan biasanya dihubungkan dengan trauma dan prosedur pembedahan. Terdapat berbagai etiologi dan kemungkinan jalur masuknya udara ke dalam canalis spinalis. Secara etiologi, pneumorrhachis diklasifikasikan menjadi iatrogenik, traumatik, dan non traumatik. Mekanisme pastinya belum diketahui secara pasti. Traumatic pneumorrhachis jarang terjadi namun diketahui sebagai komplikasi fraktur basis kranii dan trauma spinal, dan dapat diklasifikasikan menjadi tipe epidural dan subarachnoid berdasarkan lokasi udara dalam spinal canal. Tipe epidural lebih sering dilaporkan dibandingkan tipe subarachnoid. Pneumorrhachis biasanya tidak mengalami migrasi, namun akan diserap secara spontan oleh aliran darah dalam beberapa hari. Pneumorrhachis pada umumnya asymptomatic, namun dapat menimbulkan gejala terutama berhubungan dengan patologi yang mendasarinya (Behzadnia, 2016).

\section{Laporan Kasus}

Kami melaporkan pneumorrhachis traumatic pada pasien wanita usia 63 tahun yang ditemukan tidak sadarkan diri setelah jatuh di rumahnya di Surabaya dari ketinggian yang tidak diketahui. Pasien datang ke Instalasi Gawat Darurat dengan GCS 1-1-1. Foto thorax menunjukkan adanya fraktur costa multiple di hemithorax kiri, fraktur scapula kiri dan emphysema subcutis di regio cervicothoracal kiri (Gambar 1). MSCT scan thoracoabdominal menunjukkan adanya burst fracture vertebra thoracal T6 dan T10, fraktur processus spinosus T3-6, fraktur processus transversus kiri T3-7, fraktur comminutive scapula kiri, fraktur costa 5-9 kiri posterior, dengan traumatic pneumorrhachis di level T5-8. Tampak pula pneumothorax dan contussio pulmonum kiri, hematothorax kiri, pneumomediastinum sampai di level cervical, emfisema subcutis luas di cervicothoracoabdominal kiri, serta dissecting aortic aneurysm. 


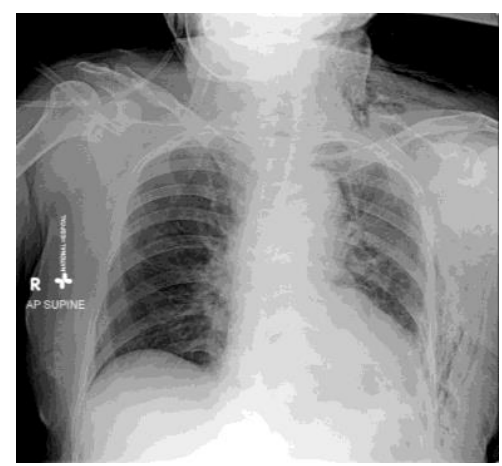

Gambar 1. Foto Thorax AP supine menunjukkan fraktur costae multiple di hemithorax kiri, fraktur scapula kiri dan emphysema subcutis di regio cervicothoracal kiri.

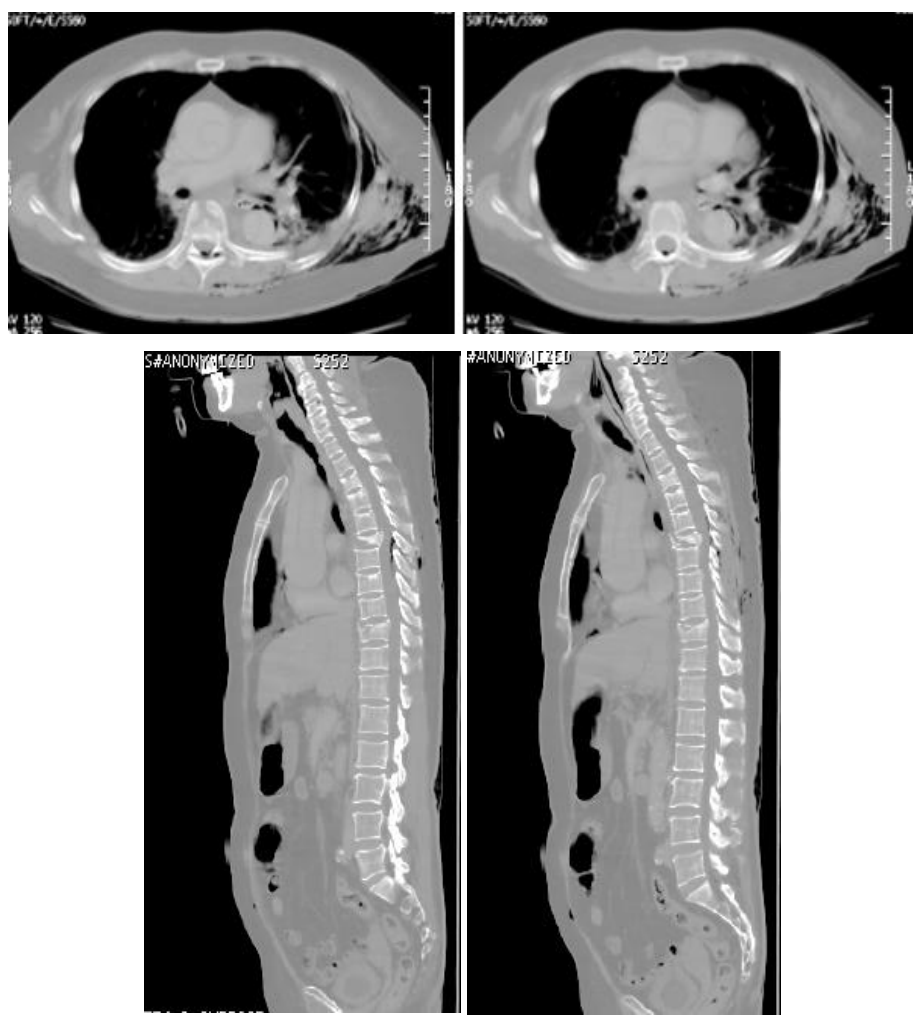

Gambar 2. CT Scan irisan axial dan sagittal menunjukkan udara pada bagian dorsal canalis spinalis setinggi level T5-8. Tampak pula burst fracture vertebra thoracal T6 dan T10, fraktur processus spinosus T3-6, fraktur processus transversus kiri T3-7, fraktur comminutive scapula kiri, fraktur costa 5-9 kiri posterior, disertai pneumothorax dan contussio pulmonum kiri, hematothorax kiri, pneumomediastinum sampai di level cervical, serta emfisema subcutis.

Pasien dirawat secara konservatif di Unit Perawatan Intensif karena kondisi umum yang buruk, dan mengalami henti jantung pada hari ketiga perawatan. Pasien akhirnya meninggal dunia setelah resusitasi gagal dan belum sempat dilakukan tindakan operatif apapun.

\section{DISKUSI}

Istilah pneumorrhachis digunakan pertama kali oleh Gordon and Hardman 
pada tahun 1977 (Gordon and Hardman, 1977) Pneumorrhachis dikenal juga sebagai intraspinal emphysema, intraspinal pneumatosis, pneumocele, pneumasaccus, pneumomyelogra, aerorachia, atau intraspinal air. Kondisi ini didefinisikan sebagai adanya udara dalam canalis spinalis dan merupakan temuan yang jarang terjadi. Penyebab pneumorrachis meliputi iatrogenic, traumatic dan non traumatic. Penyebab iatrogenic antara lain pembedahan, anestesi, dan tes diagnostic. Penyebab non traumatic meliputi degenerasi vertebral, keganasan, radioterapi, dan infeksi akibat bakteri penghasil gas. Traumatic pneumorrhachis dapat diakibatkan oleh trauma kepala, trauma spinal, maupun injuri pada cervical, thoracal atau abdominopelvis. Selain trauma, komplikasi respiratori dan barotrauma yang dapat menyebabkan peningkatan tekanan intrathoracal dapat menyebabkan pneumorrhachis secara langsung maupun tidak langsung (Kara et al, 2015).

Berdasarkan lokasinya, pneumorrhachis diklasifikasikan menjadi intradural (udara intraspinal di dalam ruang subdural atau subarachnoid) serta ekstradural (intraspinal, di dalam ruang epidural). Pneumorrhachis epidural biasanya tidak menimbulkan gejala dan seringkali merupakan temuan radiologis kebetulan, sedangkan internal traumatic pneumorrhachis seringkali fatal (Kim, 2007).

Sejauh ini tidak banyak laporan yang tersedia tentang pneumorrhachis. Gelalis et al. (2011) melakukan telaah literatur pada tahun 2011 dan hanya menemukan 37 artikel yang melaporkan 44 kasus traumatic pneumorrhachis. Artikel-artikel ini hanya memuat laporan kasus tunggal atau tidak lebih dari tiga kasus dalam satu seri. Pada 21 kasus, udara berada dalam ruang epidural dan dalam 23 kasus lainnya, udara berada dalam ruang subarachnoid. Dalam sebagian besar kasus, udara berada di satu regio spinal yang spesifik. Hanya 8 kasus yang terjadi peluasan udara ke lebih dari satu regio spinal.

Secara umum, CT scan merupakan teknik imaging pilihan untuk diagnosis pneumorrhachis, namun foto polos dan MRI juga dapat menunjukkan pneumorrhachis. Keberadaan udara dalam ruang epidural atau ruang subdural harus dibedakan, karena berkaitan dengan penanganan dan prognosis. Traumaric epidural pneumorrhachis biasanya benign dan self-limited, sedangkan subdural pneumorrhachis sering menimbulkan komplikasi tension pneumocephalus dan meningitis (Kim, 2007). Review literatur yang dilakukan oleh Goh and Yeo pada tahun 2005 terhadap 18 kasus traumatic 
ISSN 1978-2071 (Print); ISSN 2580-5967 (Online) Jurnal IImiah Kedokteran Wijaya Kusuma 8(1) : 111-116, Maret 2019

pneumorrhachis menunjukkan bahwa udara dalam spinal canal kebanyakan berada dalam ruang epidural dibandingkan dalam ruang subarachnoid (Goh and Yeo, 2005).

Pada laporan kasus ini, tipe pneumorrhachis pada vertebra thoracal adalah epidural pneumorrhachis, yang seharusnya dapat diserap sendiri oleh tubuh. Namun akibat trauma multiple yang dialaminya, pasien meninggal pada hari ketiga dalam perawatan intensif. Dikarenakan jarangnya kasus pneumorrhachis ini dan banyaknya perbedaan pathogenesis dan etiologi, maka belum ada pedoman penanganan terhadap kondisi ini. Meskipun udara dalam canalis spinalis umumnya tidak berbahaya dan dapat diserap secara spontan, kewaspadaan tetap diperlukan terhadap kemungkinan meningitis atau kebocoran carian serebrospinal terutama pada kasus pneumorrhachis subarachnoid. Pada kondisi tersebut, kemungkinan diperlukan pembedahan atau penangangan dengan temporary spinal catheter (Kim, 2007).

\section{KESIMPULAN}

Traumatic

pneumorrhachis

merupakan kasus yang jarang terjadi dan dapat disebabkan oleh berbagai penyebab. Deteksi awal menggunakan modalitas imaging yang sesuai, pemeriksaan neurologis yang lengkap, serta evaluasi rehabilitative sangat penting untuk penanganan traumatic pneumorrhachis. Traumatic pneumorrhachis seringkali didasari oleh trauma berat, seperti pada laporan kasus ini, dan oleh karenanya perlu dilakukan evaluasi mendalam termasuk untuk jejas yang menyertainya, dan ahli bedah spinal perlu memberikan perhatian penuh untuk mencegah meningitis dan tension pneumocephalus.

\section{DAFTAR PUSTAKA}

Behzadnia H, Alijani B, Ramzannwzhad A, 2016. Traumatic pneumorrhachis in a young male motor vehicle accident victim. Caspian.J.Neurol.Sci. 2(7): 49-54.

Gordon IJ and Hardman DR, 1977. The traumatic pneumomyelogram. A previously undescribed entity. Neuroradiology. 13: 107-8.

Kara H, Akinci M, Degirmenci S, Bayir A, Ak A, 2015. Traumatic pneumorrhachis: 2 cases and review of the literature. Am J Emerg Med. 33(6):861

Kim SD, Kim JS, Seong JY, Choi YG, Park IK, Baik MW, 2007. Traumatic pneumorrhachis. J Kor Neurotraumatol Soc.3(2):113115. 
Traumatic Pneumorrhachis

Sianny Suryawati

Goh BK and Yeo AW, 2005. Traumatic pneumorrhachis. J Trauma. 58(4):875-879.

Gelalis ID, Karageorgos A, Arnaoutoglou C, Gartzonikas D, Politis A, et al, 2011.Traumatic pneumorrhachis: etiology, pathomechanism, diagnosis, and treatment. Spine J. 11(2):153-157. 